\title{
scripted
}

Volume 13, Issue 1, May 2016

\section{The Online/Offline Cognitive Divide: Implications for Law}

\author{
Brian Christopher Jones*
}

While the online and offline realms continue to converge, this piece argues that a significant cognitive divide remains. This is especially the case as regards the use of social media. The structural mechanisms of these platforms encourage (and even propel) speech, which facilitates a unique cognitive environment for users; an atmosphere where individuals tend to be much more likely to engage in speech than in the physical realm. Many argue that such disinhibition is due to anonymity, but research has demonstrated that it is a more complex picture than previously believed. For the most part the law has ignored these distinct online characteristics, treating speech over social media as if it were "café" or "pub talk". In fact most of the current UK legislation used to regulate speech over the internet, including of course speech over social media, was enacted before these neoteric services came into existence. While prosecution guidelines throughout the UK have been updated to include social media considerations, it is highly debateable as to whether they have proven effective in recognising social media as a unique cognitive environment. And although policies based around technological neutrality remain increasingly attractive to law-makers, especially as the online and offline realms become less distinct, it is important to remember that law cannot properly operate based on such real or perceived eventualities.

DOI: $10.2966 /$ scrip.130116.83

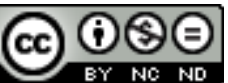

(C) Brian C. Jones 2016. This work is licensed under a Creative Commons Licence. Please click on the link to read the terms and conditions.

\footnotetext{
* Lecturer in Public Law, Liverpool Hope University, brianchristopherjones@gmail.com. The author wishes to thank Dr Kay Goodall for her plethora of insightful comments on this paper, in addition to the beneficial comments of an anonymous reader.
} 


\section{Introduction}

When it comes to speech, many of us could have split personalities; no, not in the clinical sense, of course, but in terms of how we interact online and offline. A variety of research demonstrates that individuals behave differently in these two realms: many people tend to be more forthcoming with information in the virtual world, as opposed to more traditional, "everyday" interactions. ${ }^{1}$ Although a colleague or acquaintance may seem bashful in person, their Twitter or Facebook feed could reveal a different side of their personality. The implications of this divide for law are substantial. A significant amount of public speech, which may have previously been a matter for public squares or speakers' corners - or perhaps more importantly, may have been reserved for the private realm or not uttered at all-has shifted online. Although much has been written about how the internet has affected public speech, ${ }^{2}$ little of it grapples with differences in persons' online/offline behaviour, in addition to the structure within which this speech occurs. Because law-makers in many jurisdictions have embraced the idea of "technological neutrality"3 — a belief that laws and rules for behaviours in both the online/offline realms should be equivalentarguments for any online/offline discrepancies are sometimes pushed aside. But such differences carry enormous implications for law. This article first examines the unique structure by which speech over social media occurs. It then discusses how this structure leads to an online/offline cognitive divide, and closes by considering some of its implications for law. While this article generally discusses social networking sites (SNSs), it acknowledges the variety of SNSs available. Many of these sites differ significantly in terms of the way that they are used, the way they operate, and in their levels of public/private information. While some SNSs are inherently private (Whatsapp) others lie in-between public and private (Facebook) or are fully searchable (Twitter). And although these variations are indeed significant, it is not within the remit of this paper to explore such differences.

\section{The Structural Context of Social Media Speech}

Social media providers encourage users to disclose information about themselves, to form relationships online and to enhance personal status through colourful selfexpression. But the providers do not merely encourage this: they propel users towards it and they sideline those who resist. The mechanisms they use enable the providers to

\footnotetext{
${ }^{1}$ See inter alia, GS Mesch and G Beker, "Are norms of disclosure of online and offline personal information associated with the disclosure of personal information online?" (2010) 36(4) Human Communication Research 570; AN Joinson and CB Paine, "Self-disclosure, privacy and the Internet", in AN Joinson, KYA McKenna, T Postmes and UD Reips, The Oxford Handbook of Internet Psychology (Oxford: OUP, 2007) 240; J Suler, "The online disinhibition effect" (2004) 7(3) CyberPsychology \& Behavior 321.

${ }^{2}$ See, e.g., D Solove, The Digital Person: Technology and Privacy in the Information Age (New York: NYU Press, 2004); D Solove, The Future of Reputation: Gossip, Rumor and Privacy on the Internet (New Haven: Yale University Press, 2008).

${ }^{3}$ C Reed, "Online and Offline Equivalence: Aspiration and Achievement" (2010) 18(3) International Journal of Law and Information Technology 248; C Reed, "Taking Sides on Technology Neutrality" (2007) 4(3) SCRIPTed 264.
} 
exploit fundamental cognitive biases that encourage self-disclosure. Law in Britain fails to recognise this, regulating instead the individual whose speech crosses over into transgressive behaviour such as hate speech or threats, rather than regulating the criminogenic structures that may give rise to such speech.

Too often, legal debate about harmful behaviour on social media focuses on the individual actor. ${ }^{4}$ What is insufficiently recognised is that commercial providers of social networking services incentivise people to communicate in ways that express their personal identities and disclose personal information-to become the "transparent human"5 - because providers can monetarise this data. ${ }^{6}$ But providers not only incentivise this disclosure: they impose sanctions on those who refuse to engage in these ways, by excluding them from free or subsidised services. Users are motivated to self-disclose ${ }^{7}$ through inducements that range from the hedonic (such as customisable personal spaces) $^{8}$ to the exclusionary (the requirement that data be released in order to authenticate your identity, join an online community, or filter marketing offers). ${ }^{9}$ Disclosure in itself is not necessarily unattractive to users who desire to build public profiles: ${ }^{10}$ rather the problem lies with the persistence of the data, the lack of control and the potential for its aggregation.

The rules of participation and popularity on social media encourage people to express themselves briefly (emoticons, character limits), rapidly and often (quick posting, informality in grammar and spelling) and with flair (wit, flirting). Indeed, the abbreviated length of statements and the time between receipt and transmission is central, not incidental, to some forms of social media interaction. One of the keys to "success" on Twitter is jumping into the fray fast enough that your tweets are seen at the height of interest in a topic. Debate tends to focus on the risks posed by brevity (the maximum of 140 characters in a tweet), but it has not given sufficient attention to rapidity. Naomi Baron's work on instant messaging (IM) language and SMSs concluded that the average length of IM statements is akin to a face-to-face chat, but that the frequency of transmissions between one party and the other was, she found, longer than expected, because users are often multitasking while using such services. ${ }^{11}$ Baron also found that in both IM and SMSs a number of lexical

\footnotetext{
${ }^{4}$ A recent example of this is a parliamentary report: HL Select Committee on Communications, Social Media and Criminal Offences $1^{\text {st }}$ Report of Session 2014-15 HL (2014) 37.

${ }^{5}$ B Berendt, O Günther and S Spiekermann, "Privacy in E-Commerce: Stated Preferences vs. Actual Behaviour" (2005) 48(4) Communications of the ACM 101, 101.

${ }^{6}$ J Van Dijck et al, The Culture of Connectivity: A Critical History of Social Media (Oxford: OUP, 2013), 14-18 and also for a Marxist analysis see C Fuchs, Culture and Economy in the Age of Social Media (Abingdon: Routledge, 2015), ch. 4.

7 H Krasnova, S Spiekermann, K Koroleva and T Hildebrand, "Online social networks: why we disclose" (2010) 25(2) Journal of Information Technology 109.

${ }^{8}$ P-Y Pai and DC Arnott, "User adoption of social networking sites: Eliciting uses and gratifications through a means-end approach" (2013) 29(3) Computers in Human Behavior 1039, 1047-1048.

${ }^{9}$ Joinson and Paine, see note 1 above, at 238.

${ }^{10}$ Z Tufekci, "Can You See Me Now? Audience and Disclosure Regulation in Online Social Network Sites” (2008) 28(1) Bulletin of Science, Technology \& Society 20.

${ }^{11} \mathrm{~N}$ Baron, Always On (Oxford: OUP 2008) 57.
} 
shortenings are used and punctuation is typically disregarded. ${ }^{12}$ All such time-saving strategies have remained a feature of microblogging, SMSs and other messaging platforms, and encourage, even compel users to make unqualified statements with little time for forethought (although some SNSs may compel more speech than others in this regard). These all amount to structural pressures which, if resisted, reduce the user's chance of successful participation.

Speech over social media is also a heavily nuanced endeavour that often goes beyond traditional text. Neoteric textual devices such as emoticons (including auditory emoticons, conveyed by snippets of music) and sentence-replacement "stickers"13 came to the fore in the Sally Bercow case. ${ }^{14}$ An *innocent face* emoticon that Bercow tweeted indicated to the court a defamatory accusation of paedophilia because its sardonic tone helped establish the intent behind her tweet. ${ }^{15}$ Meanwhile, the range and depth of emoticons and other icons such as stickers are growing ${ }^{16}$ (see messaging services such as WhatsApp, Line, and Facebook).

The potential impact of all this is of course heightened by permanence and searchability. These features enable individual minor acts of questionable behaviour, even over many years and places, to be brought together one day by someone else, to create a composite of statements with a more serious impact, where nuance is lost. Context is also lost: a user can engage in many different layers of interaction within a forum, and users are usually only posting to a selected, customisable group of friends or acquaintances. Even on Twitter, where everything is searchable, tweets are (often) only seen by those "following" them. ${ }^{17}$ Such levels further muddle the distinction between public and private expression. Both the English guidelines and the Scottish guidance on social media prosecutions do treat intention not to communicate to a wide audience as relevant, although not decisive. ${ }^{18}$

\footnotetext{
${ }^{12} \mathrm{Ibid}$, at 152-160.

${ }^{13}$ H Tabuchi, "No Time to Text? Say It With Stickers" (25 May 2014) New York Times, B1, at http://www.nytimes.com/2014/05/26/technology/no-time-to-text-apps-turn-to-stickers.html?_r=0 (accessed 27 April 2016).

${ }^{14}$ Lord McAlpine of West Green v Bercow [2013] EWHC 1342. Sally Bercow is the wife of the Speaker of the House of Commons. On this, see P Bernal "A defence of responsible tweeting” (2014) Communications Law 12.

15 J Agate, "McAlpine, the Attorney General and the Defamation Act - social media accountability in 2013” (2013) 24(7) Entertainment Law Review 235.

${ }^{16}$ Tabuchi, see note 13 above.

${ }^{17}$ All tweets are searchable unless the user has selected to make their tweets private. In particular, if hashtags are added to tweets (\#), others can easily trace all the tweets containing that hashtag.

18 Crown Prosecution Service guidelines,

http://www.cps.gov.uk/legal/a_to_c/communications_sent_via_social_media/ (accessed 27 April 2016). Scottish guidance, $\quad$ p. 9 http://www.copfs.gov.uk/images/Documents/Prosecution_Policy_Guidance/Book_of_Regulations/Fina 1\%20version\%2026\%2011\%2014.pdf (accessed 27 April 2016).
} 


\section{The Online/Offline Cognitive Divide}

There may come a time when the separation between the online and offline worlds is indistinct, and that may indeed be what some technology/social networking companies desire: a harmonious connection between the physical and virtual world. Some scholars have argued that these worlds are already becoming indistinct: John Inazu notes the "dynamic line" between the virtual and non-virtual, ${ }^{19}$ and Klaus Jensen concludes that after being regarded as "an extraordinary cyberspace", the "Internet has been going through a process of becoming ordinary". ${ }^{20}$ Andrew Murray even notes that "[p]eople treat SNPs [social networking providers] like private conversations and do all the things they normally would in private discussion with friends". ${ }^{21}$ Indeed, there is little doubt that the online world is "entirely real" ${ }^{22}$; so real that many activities previously performed offline (dating, shopping, even getting an education) can now be performed online. Yet the newfound harmony between online/offline activities is often at odds with the distinct behavioural differences seen online, as opposed to offline.

It is also important to understand the cognitive aspects of these developments, which again are not necessarily matters of reckless character, but are fundamental human characteristics. Although they may be becoming more intertwined as technology advances, there remains a sufficiently strong case against the presumption that the physical and virtual worlds mimic one another. The online disinhibition effect, including but also beyond the important aspect of anonymity, provides evidence that there are distinct behavioural patterns and norms exhibited online. There are also fundamental differences in the mechanisms people use to establish online and offline trust.

Initial research in this area focused on human-computer interaction as a relationship between human and machine. ${ }^{23}$ Now, with the omnipresence (in most developed nations) of the internet and social media, research is focusing on the machine as being an intermediary, as the physical and virtual worlds gradually blend into one another. Yet over the past two decades a significant body of empirical research has found that people are more uninhibited online than in face-to-face communications. ${ }^{24} \mathrm{~A}$ significant, if not disproportionate, part of the discussion regarding online speech revolves around the concept of "anonymity", including extensive discussion about how it should be dealt with by the courts. ${ }^{25}$ Many commentators believe this to be the

\footnotetext{
${ }^{19}$ J Inazu, "Virtual Assembly” (2013) 98(5) Cornell Law Review 1093, 1112.

${ }^{20}$ K Jensen, "New Media, Old Methods - Internet Methodologies and the Online/Offline Divide", in Consalvo and Ess (eds) The Handbook of Internet Studies (Oxford: Wiley, 2011), 47

${ }^{21}$ A Murray, Information Technology Law: The Law and Society (2nd ed)(Oxford: OUP, 2013), 138.

22 SA Golder and MW Macy, "Digital Footprints: Opportunities and Challenges for Online Social Research" (2014) 40 Annual Review of Sociology 129, 143.

${ }^{23}$ A Light and I Wakeman, "Beyond the interface: users" perceptions of interaction and audience on websites" (2001) 13(3) Interacting with Computers 325, 326.

24 AN Joinson, "Disinhibition and the Internet", in Gackenbach (ed.) Psychology and the Internet: Intrapersonal, Interpersonal, and Transpersonal Implications (San Diego: Academic Press, 2007), 76.
} 
driving factor behind toxic (internet) disinhibition. I disagree, and hope to provide more context to this important discussion.

A distinct "disinhibition effect", outside the parameters of anonymity, has been found by many. Gustavo Mesch and Guy Beker conclude that "it appears that the tendency to disclose more personal information online is not restricted to communication purposes and is common in any online behavior". ${ }^{26}$ Researchers and journalists often refer to this as the "Gyges effect". Such evidence has been found in a range of studies examining chat rooms, survey responses, emailing and many other situations. ${ }^{27}$ Some users have even reported an "online self" and an "offline self", maintaining that these iterations are vastly different from one another. ${ }^{28}$ Others believe the norms and values of the offline world do not transfer to the online world. ${ }^{29}$ Azy Barak and Liat Hen observe:

The online disinhibition effect is assumed to be a product of several psychological factors that operate in cyberspace and have a great impact on people's behavior. The main factors are considered to be anonymity, invisibility, lack of eye contact, neutralization of people's status, asynchronicity as a major road block of communication, and textuality of communication. As a result of these factors, expressed dynamically but whose relative powers and directions are still to be empirically determined, an individual goes through a disinhibition process, whereby behaviors (including verbal expressions) not normally displayed in the physical environment, or not as intensively or prevalently, are expressed and become more frequent on the Internet. ${ }^{30}$

Microblogging social media in particular has received a large amount of criticism regarding its potentially toxic effects. A prominent example of this was the reaction to Caroline Criado-Perez and MP Stella Creasy as regards women on British bank notes. Criado-Perez's successful campaign was met with overwhelming hostility, in which users reacted negatively and sometimes violently: some made rape threats while others were explicitly misogynistic. ${ }^{31}$ After Creasy defended Criado-Perez, she was met with similar threats, even death threats. She was sent a picture of a masked man

25 See, e.g., B Murchison, "Anonymous speech on the internet", in D Hunter, R Lobato, M Richardsom, and J Thomas (eds) Amateur Media: Social, Cultural and Legal Perspectives (Oxford: Routledge, 2013), 187.

${ }^{26}$ Mesch and Beker, see note 1 above, at 572.

${ }^{27}$ Joinson and Paine, see note 1 above, at 240.

${ }^{28}$ Suler, see note 1 above, at 324-325.

${ }^{29}$ Mesch and Beker, note 1 above, at 574, citing H Rheingold, The Virtual Community (Cambridge: MIT, 1993).

${ }^{30}$ A Barak and L Hen, "Exposure in cyberspace as means of enhancing psychological assessment", in A. Barak (ed), Psychological Aspects of Cyberspace: Theory, Research, Applications (Cambridge: CUP, 2008) 135.

${ }^{31}$ The Guardian, "Two jailed for Twitter abuse of feminist campaigner" (24 January 2014), available at http://www.theguardian.com/uk-news/2014/jan/24/two-jailed-twitter-abuse-feminist-campaigner (accessed 27 April 2016). 
brandishing a knife, and also received threats that she was going to be beheaded. ${ }^{32}$ Of course, none of these threats came from face to face communication; all were delivered pseudonymously via Twitter. Yet such toxic behaviour may not arise merely because of anonymity or pseudoanonymity. For example, Lapidot-Lefler and Barak have found that a lack of eye-contact, not anonymity or invisibility, was the "chief contributor to the negative [toxic] effects of online disinhibition". ${ }^{33}$ This further highlights that the structural aspects of such communication could have much more influence than previously thought. Indeed, lifting many of the "geographical and temporal constraints of face-to-face communication" 34 has not happened seamlessly, and thus may require more time for norms to develop and certainly further understanding by the law.

Although anonymity and invisibility have (perhaps mistakenly) dominated the disinhibition debate, ${ }^{35}$ researchers have also explored whether different norms of disinhibition/disclosure are displayed online and offline. Comparing a large sample of American adolescents, Mesch and Beker found that computer-mediated communication produces a noticeable generative effect. In particular, "[n]orms of offline identity information disclosure were not related to norms of online identity disclosure, indicating that they are not associated with online behavior". ${ }^{36}$ Ultimately, the researchers concluded that, "online realms in general and CMC (computer mediated communication) in particular constitute a separate normative realm". ${ }^{37}$ This finding supports my position that the online world, although abundantly connected to the physical world, is a social space in its own right. Mesch further argues that "online behavior is conceived as different and even separate from one's offline norms and motivations.... some Internet attributes such as the lack of cues, controllability and anonymity provide individuals with the opportunity to disclose more intimate and personal information". ${ }^{38}$ Far from knowing less about others online, we may learn what was once the sort of information shared only with a person's closest confidantes, if at all. Supporting their arguments about the continuum of obscurity, Hartzog and Stutzman point out that human cognitive groups have historically been far smaller than the groups of associates in online life, and that obscurity has thus hitherto been the norm. ${ }^{39}$

\footnotetext{
${ }^{32}$ A Topping and B Quinn, "Stella Creasy receives Twitter photo of masked, knife-wielding man" (6 August 2013), The Guardian, available at http://www.theguardian.com/technology/2013/aug/06/stellacreasy-twitter-photo-masked-man-knife (accessed 27 April 2016).

${ }^{33} \mathrm{~N}$ Lapidot-Lefler and A Barak, "Effects of anonymity, invisibility, and lack of eye-contact on toxic online disinhibition" (2012) 28 Computers in Human Behavior 434.

${ }^{34}$ Golder and Macy, see note 22 above, at 143.

35 EE Hollenbaugh and MK Everett, "The Effects of Anonymity on Self-Disclosure in Blogs: An Application of the Online Disinhibition Effect" (2013) 18(3) Journal of Computer-Mediated Communication 283.

${ }^{36}$ Mesch and Beker, see note 1 above, at 588.

${ }^{37}$ ibid.

38 GS Mesch, "Is online trust and trust in social institutions associated with online disclosure of identifiable information online?” (2012) 28(4) Computers in Human Behavior 1471, 1476.
}

${ }^{39}$ Hartzog and Stutzman, “The Case for Online Obscurity” (2013) 101(1) California Law Review 1, 6. 
Georg Simmel long ago observed that trust is "one of the most important synthetic forces within society", ${ }^{40}$ and this is also present in virtual worlds. Trust among one's friends or "followers" is also a key issue in understanding how individuals behave over SNSs, as is the generalised trust users invest in the wider online world. Trust over the internet and SNSs in particular involves two distinct but inter-related levels: (i) the trust of one's online friends, acquaintances or followers, and (ii) trust in the service provider or company that the user is revealing information to. Regarding the latter, Gordon and Macy note that a growing body of research finds anonymising or encrypting data insufficient for protecting privacy. ${ }^{41}$ If privacy considerations are lost to the monetarisation of data, this finding is especially troublesome, and something the law should take into consideration. It should also not be forgotten that "good business practices have important ramifications for the long-term well-being of societies", including virtual ones. ${ }^{42}$ Regarding the former, opportunities for misperception among users already created by the very low level of social cues online are worsened by a phenomenon familiar to psychologists: the false-consensus effect ${ }^{43}$ : that people tend to overestimate the extent to which others share their perceptions of the social world. This cognitive bias has been found to affect a huge range of perceptions from ethics and values to interpretations of everyday events, and unsurprisingly has also been found on the internet. ${ }^{44}$ Nevertheless, trust remains an interconnected issue affected by a range of other elements.

There is also a gap between actual privacy on social media and perceived notions of privacy that contributes to the disinhibition considered above. Howard Rheingold has observed that the internet brings a "decentering of place"; ${ }^{45}$ Inazu calls it "presence without physicality". ${ }^{46}$ Scholars have found that people commonly have a heightened sense of concern regarding their privacy, but often do not take the necessary steps to protect it. ${ }^{47}$ Novice SNS users are likely to take a cautious approach early on, and reveal more as they increasingly use the service. This is understandable given that in many respects, engagement in social media is a highly private endeavour. People post in their homes on personal computers, on their phones, pads or other devices, and have personalised pages ${ }^{48}$ for most of their social media sites. But speaker location (in terms of physical presence of the user/speaker), which is a key aspect of traditional

\footnotetext{
${ }^{40}$ KH Wolf, The Sociology of Georg Simmel, (Glencoe: Free Press, 1950), 318.

${ }^{41}$ Golder and Macy, see note 22 above, at 141.

${ }^{42}$ Muntz, "Effects of Internet Commerce on Social Trust (2009) 73(3) Public Opinion Quarterly 439, 455.

${ }^{43}$ Marks and Miller, "Ten years of research on the false-consensus effect: An empirical and theoretical review” (1987) 102(1) Psychological Bulletin 72.

${ }^{44}$ Wojcieszak, "False Consensus Goes Online: Impact of Ideologically Homogenous Groups on False Consensus" (2008) 72(4) Public Opinion Quarterly 781.

${ }^{45}$ H Rheingold, The Virtual Community: Homesteading on the Electronic Frontier (Cambridge: MIT Press 1993), 349.

${ }^{46}$ Inazu, see note 19 above, at 1108.

47 YJ Park, SW Campbell and N Kwak, “Affect, cognition and reward: Predictors of privacy protection online” (2012) 28(3) Computers in Human Behavior 1019, 1020.

${ }^{48}$ Pai \& Arnott, see note 8 above, at 1047-1048.
} 
public discourse, is a lesser feature in online speech — until one crosses the indistinct borders of legality.

\section{Implications for the Law}

The cognitive divide between the online/offline worlds suggests that "cyberspace [is] a psychologically unique social environment. People, in general, behave in it more freely and more openly than in their offline, physical environment $[\mathrm{s}]$ ". ${ }^{49}$ Indeed there appears to be a "natural human tendency to treat cyberspace" differently, as a place where standards of behaviour may change from the physical world.$^{50}$ Thus the norms and values of the offline world do not easily translate to online platforms. Yet many individuals have been convicted of offences involving what Rowbottom would define as low-level speech: "amateur content that is spontaneous, inexpensive to produce and is often akin to everyday conversation". ${ }^{51}$ Low-level speech can be threatening, target individuals for harassment or be grossly offensive. However it may also be less serious and merit a lesser response, being of the sort that would previously (being expressed verbally) not have attracted criminal censure.

American jurists have offered a constructive critique of the traditional distinction made between high and low-value speech (which depends on whether the speech engages with matters of democratic importance) ${ }^{52}$ Rowbottom has argued that a greater distinction in Britain should be made between high and low-level speech (examining whether or not it is "professionally produced, aimed at a wide audience ... well-resourced and researched in advance" ${ }^{, 53}$ ). Judgments about low-level speech should focus less on the benefit to the audience and more on the right of the speaker to participate in democratic communication. ${ }^{54}$ There is concern about whether the CPS, and others, are respecting these thresholds. ${ }^{55}$

\footnotetext{
${ }^{49}$ Barak and Hen, see note 30 above, at 135.

50 Reed, "Online and Offline Equivalence", see note 3 above, at 253. Although, Reed's ultimate message here advocates equivalence, in that "[t]he standards to which such [online] actors will be held to are to be broadly the same as the standards offline".

51 J Rowbottom, “To Rant, Vent and Converse: Protecting Low Level Digital Speech” (2012) 71(2) Cambridge Law Journal 355, 357.

52 See for instance R Post "The Constitutional Concept of Public Discourse: Outrageous Opinion, Democratic Deliberation and Hustler Magazine v. Falwell" (1990) 103(3) Harvard Law Review 603; CL Estlund "Speech on Matters of Public Concern: The Perils of an Emerging First Amendment Category" (1990) 59(1) George Washington Law Review 1; F Schauer "The Boundaries of the First Amendment: A Preliminary Exploration of Constitutional Salience" (2004) 117(6) Harvard Law Review 1765.

${ }^{53}$ Rowbottom, see note 51 above, 357.

54 J Rowbottom "In the Shadow of the Big Media: Freedom of Expression, Participation and the Production of Knowledge Online" (2014) PL 491, 495.

55 See e.g., D Bunting, "Jake Newsome - Another social media jailing over an Ann Maguire posting”, UK Criminal Law Blog (4 June 2014), available at http://ukcriminallawblog.com/jake-newsomeanother-tweeter-jailed-for-ann-maguire-posting/ (accessed 27 April 2016); see also L Harris, "Defendant who told judge 'suck my cock' on Facebook to be re-sentenced", UK Criminal Law Blog (16 Feb 2016), available at http://ukcriminallawblog.com/defendant-who-told-judge-suck-my-cock-onfacebook-to-be-re-sentenced/ (accessed 27 April 2016).
} 
Other scholars have remarked on the need for the law to be illuminated by deeper understanding and analysis when it comes to new technologies and social media. McGoldrick writes:

The rapid evolution of SNSs certainly demands imaginative and informed rethinking about their legal regulation. In legal terms communicating via SNSs is clearly not the equivalent of oral conversations with friends in a cafe, a bar or a public house. There is a permanent written record. There is also a potentially much wider audience... 56

Nevertheless the misconceived café/pub talk analogy seems to have taken hold among the judiciary. Rowbottom cites several examples of judges analogising online comments to different forms of casual speech, such as "chatting in a bar", "pub talk" and "saloon-bar moanings". ${ }^{57}$ Rather than considering inherent differences in online and offline communication, judges have drawn from pre-existing notions of discourse that align with the technological-neutral arguments noted above. Thus we have not yet seen the fundamental legal innovations needed to deal with the internet, and social media in particular. This is especially problematic given social media users' minimal control over the destinations of their statements. As McGoldrick has observed, "[t]he line between individual and small group communication on one side and mass communication on the other is gradually fading". ${ }^{58}$ When people engage in abusive speech online, they therefore face criminal prosecution, sanctions by their employer, widespread public exposure and shaming and/or being excluded from SNSs. They may seek to defend themselves by arguing that they believed the space to be private, but law accords them little right of privacy (beyond the minimal amount of protection offered by the due process principle in criminal procedural law). They may seek to assert their right to obscurity (having embarrassing or misleading data deleted), but mostly law does not provide this either. ${ }^{59}$

\footnotetext{
${ }^{56}$ D McGoldrick "The Limits of Freedom of Expression on Facebook and Social Networking Sites: A UK Perspective" (2013) 13(1) Human Rights Law Review 150. My emphasis.

${ }^{57}$ See the cases cited in Rowbottom, note 51 above, at 377 . Academics in the US have also done this. See BJ Linnekin, "“Tavern Talk" and the Origins of the Assembly Clause: Tracing the First Amendment"s Assembly Clause Back to Its Roots in Colonial Taverns" (2012) 39(3) Hastings Constitutional Law Quarterly 593.
}

${ }^{58}$ McGoldrick, see note 56 above, at 151 . He goes on to observe:

[s]o too is the line between individual communications and those by organisations and institutions. It is not really credible to apply the high standards of journalism and broadcasting imposed by human rights law on mass communication organisation and institutions to individuals. The law will have to adapt. This will happen both in terms of substantive law and remedies that afford effective legal protection.

\footnotetext{
${ }^{59}$ Especially now that it is so easy to take screenshots on any type of device that operate SNSs. And while the "right to be forgotten" ruling (Google Spain SL, Google Inc. v Agencia Española de Protección de Datos, Mario Costeja González, C-131/12 (13 May 2014)) does allow for certain information/stories not to arise on search engines, it sometimes does not delete that information from the original sources (e.g., in the case of a news story on a newspaper website, which may still carry the work, even though the search engine will not include such an article in its results). This is because the right to privacy must be balanced with the right to freedom of expression. However, in most cases regarding SNSs it does allow for users to request full deletion of their personal data located on such services.
} 
The main traditional right individuals could draw upon is the right to freedom of expression. But this right is available only in forums that are designated as public space, or where a person is engaging in protected speech such as political expression. Almost all online forums are pseudo-public space, because they are corporately owned and there is no concept of the online Speaker's Corner, ${ }^{60}$ the protected public forum online where speech by minor figures may be heard in passing by a significant proportion of citizens. And although the European Court of Human Rights has acknowledged that "the Internet has now become one of the principal means by which individuals exercise their right to freedom of expression and information", ${ }^{61}$ it has yet to define major SNSs as public forums. Some jurisdictions have (rightly) begun implementing constitutional protections regarding the internet. The German Federal Court of Justice and French Conseil constitutionnel have held that there is a fundamental right of access to the internet. ${ }^{62}$ I have previously argued that even though social media has gone through periods of being seen as "democracyenforcing" and "rights-infringing", it could eventually be recognised as a human right, given that it touches on the important freedoms of expression, association and information. ${ }^{63}$ But such recognition would also have to appreciate its distinctive characteristics.

\section{Conclusion}

The structural and cognitive aspects of social media use should not be lost on the law. Policies advocating online/offline equivalence are certain to be important going forward, ${ }^{64}$ especially as the two realms become more intertwined and less distinct. But law cannot properly operate based on such real or perceived eventualities; after all, and most significantly, law governs the present. Users of SNSs are structurally compelled into engaging in speech-sometimes harmful speech. And indeed researchers have found that, outside of mere anonymity, the cognitive aspects of the online realm produces a unique environment, where individuals divulge more than they do in the physical realm. The law has not accounted for these characteristics, often treating such speech as "pub talk" or other casual speech; and given the

\footnotetext{
${ }^{60}$ As Noveck observed, there is "no Central Park in cyberspace" (BS Noveck, "Designing Deliberative Democracy in Cyberspace: The Role of the Cyber-lawyer" (2003) 9 Boston University Journal of Science and Technology Law 1, 24).

${ }^{61}$ Yildirim v Turkey ECtHR (18 December 2012).

${ }^{62}$ G Moody, "German Court Recognizes That An Internet Connection Is Now Indispensable For Modern Life", Tech Dirt (25 Jan 2013), available at https://www.techdirt.com/articles/20130125/07585121787/german-court-recognizes-that-internetconnection-is-now-indispensable-modern-life.shtml (accessed 27 April 2016); N Lucchi, "Access to Network Services and Protection of Constitutional Rights: Recognizing the Essential Role of Internet Access for the Freedom of Expression" (2011) 19(3) Cardozo Journal of International and Comparative Law 645; see also the discussion of professional media outlets in T Kenyon "Assuming Free Speech" (2014) 77(3) MLR 379, 391-393.

${ }^{63}$ BC Jones, "Is Social Media a Human Right? Exploring the Scope of Internet Rights", International Journal of Constitutional Law Blog (5 Dec 2014), available at: http://www.iconnectblog.com/2014/12/is-social-media-a-human-right-exploring-the-scope-of-internetrights/ (accessed 27 April 2016).

${ }^{64}$ See, e.g., Reed, “Online and Offline Equivalence”, note 3 above.
} 
difficulties in keeping up with technology, legal regulation of it is often hopelessly out of date. As a 2014 Lords Communications Committee report noted when discussing social media prosecution options, even though the Director of Public Prosecutions has issued "clear and accessible" guidelines on social media prosecutions, most of the laws being used to prosecute such cases "pre-date the invention of social media". 65 These legal "adaptations"-presumably based around notions of technological neutrality and online/offline equivalence - appear to have been the preferred method for prosecutors, judges and lawmakers, but they are certainly not the "imaginative and informed re-thinking" that McGoldrick suggested. ${ }^{66}$ Should the legal establishment ever take on such a complicated and multifaceted project, the structural and cognitive characteristics of social media - and the internet more generally — must be taken into consideration.

\footnotetext{
${ }^{65}$ Lords Social Media and Criminal Offences Report, see note 4 above, at 7 . And further, the report thought that this was acceptable.
}

${ }^{66}$ McGoldrick, see note 56 above. 